exclude those which are noted as premature, the result is a much better one, $2.5 \%$.

To the vital statistics of many of our communities $I$ am hardly justified in referring, by reason of their admitted imperfection. In the State of Michigan but $2.4 \%$ are recorded, and in the city of St. Louis we find the rate varying from 3.8 to $8 \%$. In both instances, however, the investigators call attention to the uncertainty of the data, so we may well ignore these two extremes (Table III).

TABLE III.-STILLBIRTHS PER 100 BIRTHS.

\begin{tabular}{|c|c|c|c|c|}
\hline \multirow[b]{2}{*}{ 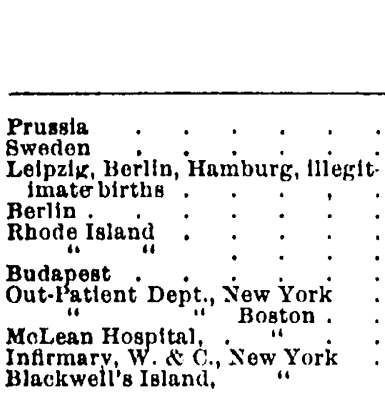 } & \multicolumn{2}{|c|}{$\begin{array}{l}\text { Before the } \\
\text { antiseptic } \\
\text { era. }\end{array}$} & \multicolumn{2}{|c|}{$\begin{array}{l}\text { Recent } \\
\text { Recorts. }\end{array}$} \\
\hline & $\mid \begin{array}{c}1858-1867 \\
1861-1870 \\
1870 \\
1872-1888 \\
1872-18 \times 8 \\
1854-1880\end{array}$ & $\begin{array}{l}4.2 \\
3.3 \\
7 . \\
3.8 \\
3.6 \\
3.8\end{array}$ & $\begin{array}{r}3.4 \\
3.6 \\
3.9 \\
3.6 \\
3 . \\
5.4 \\
51 \\
10.7\end{array}$ & $\begin{array}{c}1884-1895 \\
1884-1805 \\
\overline{1806} \\
1890-1896 \\
1898-1901 \\
1874-1901 \\
1901 \\
1001\end{array}$ \\
\hline
\end{tabular}

The impress made upon the statistics of stillbirths by the advance of obstetric art is evidently but slight. Throughout Prussia there seems to be a trifling but gradually continuing decrease from $4.2 \%$ in the early ' 60 's to $3.4 \%$ in 1895 , in Berlin. At the present day we find $3.9 \%$ in Budapest, $4 \%$ in Italy, $3.6 \%$ throughout the State of Rhode Island, with hardly a change from 1854, and the same, $3.6 \%$, at the present day, in the Out-Patient Department of the Iying-in Hospital of the city of New York; yet Sweden recorded but $3.3 \%$ from $1861-1870 ; 3 \%$, the lowest figure noted, occurred in the Out-Patient Department of the Boston Lying-in Hospital, over $5 \%$ in the hospital itself; and for 1901, 5.1\% in the New York Infirmary for Women and Children; $10.7 \%$ at Blackwell's Island, Metropolitan Hospital, and at the City Hospital, $6.5 \%$.

$$
\text { ( To be continued.) }
$$

\section{AMAUROSIS (ATROPHY OF THE OPTIC NERVE) AND ITS TREATMENT BY THE SUBCUTANEOUS INJECTION OF STRYCH- NIA. ${ }^{1}$ \\ BY HABKET DKHUY, M.D., BOBTUN.}

Probably no disease of the eye was more frequently met in the group classed by our prede. cessors under the general head of "Amaurosis" than progressive optic nerve atrophy. And although the progress of science has enabled us to give this affection its own proper name, to watch its development and, in some cases, ascertain its cause, the prognosis is hardly less gloomy and the efficacy of treatment but little more demonstrable than was the case half a century ago. The ophthalmoscope gives us an opportunity of witness-

1 Read before the New England Ophthalmological Boclety, Fob. 11, 1002 . ing the change, the test-types and the perimeter of noting advance, but in the matter of therapeutics we have but slight improvement to record.

The recent simultancous occurrence of several cases of optic nerve atrophy in my own practice, and a rather unusual opportunity offered for their study and observation, has led me to look over my notes of similar cases met with during my professional life. I have thus been enabled to collect some statistics not found in the books, a recital of which, although it may add but little to our practical knowledge of the disease, will not, I trust, be without interest.

It is not often that the surgeon has an opportunity of following a fatal case to its termination. I therefore give a brief history, which may serve as a typical one.

Patient a stout, well-preserved man of 48 . He had been captain of a whaler, and only recently retired from the sea. Habits temperate, health always excellent. Within a year had noted the gradual loss of the sight of left eye, vision simply growing dim and gradually almost disappearing. For six months he had observed failure of the remaining eye, and this brought him to me. His own attention bad been called to the progressive contraction of the visual field, and he had just lost the power of reading. On examination the left eye, externally normal save for a somewhat dilated pupil, was found to possess only quantitative perception of light. The nerve was of chalky whiteness, veins large, arteries greatly contracted, no excavation. Vision of right eye .5, visual field much contracted upwards and inwards, nerve somewhat atrophic, but the process much less advanced than was the case in the other eye. To make the account of this case as brief as possible, the disease steadily progressed, despite all treatment. The field slowly contracted, the nerve grew whiter and whiter, central vision became more and more impaired. As the patient expressed it, "I see everything through a mist, that is gradually thickening as the field contracts." He went home, but wrote me from time to time. His health continued excellent, his strength unabated and his appetite good. Two years later he was blind. Four years afterward he was again heard from. In the interval, assisted by a competent clerk, he had continued to perform his duties as registrar of deeds in his native town. He, moreover, edited a paper, besides writing up and publishing his adventures as a whaleman. His memory continued good and his mind was never in the least affected. Several years later he died of, I think, pneumonia.

The foregoing may be taken as a representative case of the class in which blindness proceeds from this cause and the general health remains unimpaired. Such an instance is by no means infrequent. Of course many others depend on local or general disease, on excesses in living, the abuse of venery, the abuse of alcohol or tobacco. But there are many that can be classed under none of these heads. 
Referring to the notes of my own practice, I his footsteps. But the credit of introducing this have been able to collect the following statistics: form of treatment by local subcutaneous injection There are notes of 117 cases. Of these 78 were belongs indisputably to Nagel of Tubingen, who, males, average age 43.7 ; 38 were females, average in 1872 , published a monograph on the subject. age 37.7. Both eyes were affected in 86 cases; This pamphlet, no doubt familiar to many of you, one only in 31 cases. In 71 cases there was no gives numerous cases of optic nerve atrophy, ochistory to be traced. In the remaining $46 \mathrm{I}$ curring in both the young and those of middle found the following probable causes: Abuse of age, all sunilarly treated and with the results alcohol and tobacco, 11 ; syphilis, 8; blow on carefully recorded. In certain instances he claims head, 9 ; brain disease, 6 ; apoplexy, 1 ; epilepsy, 1 ; increase in the visual acuteness, in the area of the locomotor ataxia, 1; meningitis, 2; optic neuri- field and even in the appearance of the nerve tis, 2; erysipelas, after lachrymal abscess, 1 ; itself. So far as the cases could be followed up, mumps (both cases children), 2 ; following pregnancy, 1 ; tumor of pituitary body, 1 .

Coming now to the question of possible treatment of what is undoubtedly one of the most fatal of diseases, we are met with a sweeping statement by one of our foremost authorities. I find in the New York Medical Record of Nov. 16,1901 , an account of the proceedings at a meeting of the Acadamy of Medicine, in which occur the following remarks made by Dr. H. Knapp: As to the futility of treatment in atrophy of the optic nerve, he begged leave to tell his own opinion and that of the late Dr. Alfred Loomis, who had asked his opinion about the therapeutic value of electricity in tabic and other atrophies. He, the speaker, answered he thought that electricity, in these diseases, was next to quackery, to which Loomis replied: "That is too far off." It would seem that other methods -of treatment are intended to be included in this condemnation.

With all modesty, I beg to differ from the foregoing statement, and to base this on certain facts.

I have been able to subject 26 of the foregoing patients to courses of treatment, and to follow up the results. And they may be thus tabulated: Not relieved, 15, the disease progressing and terminating in blindness; doubtful relief, 1 ; temporary relief, 2 ; appreciably relieved, 8 ; and by relief I mean an evident cessation of the onward march of the disease, with occasionally a slight increase in the limits of the field and the acuity of vision. In each instance the case was held under observation a length of time that, judging from the previous progress of the disease, would have afforded an opportunity for manifest failure of sight, and in which this would actually have occurred.

The amelioration thus obtained has been due to the use of a single drug, strychnia, applied in gradually increasing doses in the temples by subcutaneous injection.

The use of strychnia in amblyopia and amaurosis dates back to the early part of the nineteenth century, Thomas Shortt of Edinburgh having first brought it into notice. He used large doses, applied endermatically and as near the eye as possible, and claimed striking results. He flourished long before the invention of the ophthalmoscope, but as far as symptoms are concerned it seems probable that some of his cases Becker of IIeidelberg applied the method in a case of embolus of the central retinal artery, and obtained disappearance of the cherry red spot, enlargement of the field and a return of normal vision. Horner of Zurich reported a case of white atrophy combined with retinal hemorrhages, where vision quadrupled, the appearance of the nerve remaining unchanged.

In 1873 von Hippel of Königsberg published a brochure containing a long list of cases, and summed up his experience in the following words: "These facts convince me that in diseases of the optic nerve, where our therapeutics have hitherto been of no account, we possess in strychnia a drug which in many cases arrests advancing disease, and in others materially improves the much impaired vision; while its effect is not limited to those cases in which the ophthalmoscope shows as yet no evident anatomical change in the nerve, the fact being that in actually developed atrophy we may obtain most astonishing results, always supposing that there remains good perception of light."

In 1876 Haltenhoff of Geneva also brought out a pamphlet on the subject and advocated the treatment. Since that time, while many works on ophthalmology still advise the internal administration of strychnia, less and less stress is laid on local subcutaneous injection, and the impression is largely given that we can get the same effects by giving the drug by the mouth. As far as I am aware, the method of Nagel has at present but fow, if any, adherents in our own community, a fact which is not perbaps extraordinary when we look over some of the accepted textbooks of the day. Noyes mentions the plan of Nagel, but indicates his own preference for the internal administration of the drug. Berry gives no treatment whatever. The same is true of the smaller work of Norris and Oliver, while even in their larger system of diseases of the eye the strychnin treatment receives no mention. Among our own writers De Schweinitz alone comes out with the advice that the drug be administered in full doses, and states that the hypodermic method affords the best result. Fuchs, edition of 1898 , of course alludes to the method of Nagel, but expresses some doubt as to the permanency of the effect on the nerve caused by the strychnia, while admitting its immediate effect.

It is most reasonable to suppose that the prefwere optic nerve atrophy. Others followed in erable method of administering the strychnis is 
the hypodermic. When a drug of this kind is given by the mouth the rapidity of the general effect inust depend on the contents of the stomach and the state of digestion. And if a supra-orbital or a facial neuralgia is most quickly relieved by au injection of morphia made in the immediate vicimty of the nerve affected, it stands to reason that the effect of the strychnia must be the more rapid, to say the least, when it is injected in close proximity to the nerve it is desired to stimulate.

As has been stated, there were 26 cases in which the strychnin treatment was carried out. In 15 of these no effect whatever was produced and the disease progressed to blindness. But in 8 , about $30 \%$, the result was fairly encouraging. Many of these patients came from a distance, and I ultimately lost sight of them, nor have I been able to trace their subsequent history. lisut they were all so much encouraged when they left the city that I cannot help feeling that I should have heard again had there been subsequent failure, especially as it is my habit to urge such patients to write to me, whether they are intending to return or not.

Case I. A Maine lumberman, age 43 ; health excellent. Rapidly progressing atrophy. Right eye, vision .3 , left counts tingers in $50 \mathrm{~cm}$.; no letters can be seen. Two months later, vision right, nearly .5 ; left makes out 60 of Monoyer in $80 \mathrm{~cm}$. ' $I$ 'wo year's later writes that his vision has failed, if at all, very slightly.

Casri II. Female, age 25. No history. Vision right .4 , left not quite .8 ; one course of injections. At its close, vision right .7, loft 1 . 'Two months later was holding her own.

CAsk III. Man from Nova Scotia, age 60. Under strychnin injections his visiou doubled, rising from .2 to .4. He died suddenly in the course of the same year, but I have no reason to suppose that he lost any of the vision he had gained.

Case IV. Nan, age 32. One eye entirely blind, nerve atroply marked in the other. Vision at first .6, after treatment, noarly .8. Six months later had lost no ground. Previous to treatment failure had been rapid. At oud of a year, still improving, as he writes.

Casic V. Man, age 68 . Vision of each eye failing for three years. Vision before troatment, right .3, left .2. One course of injections. This patient was seen in consultation and but once. But his physician reported that ho held his own seven months afterwards.

Case VI. Female, age 64. Right eye gone, left rapidly falling. A single course of injections. This case, too, was seen in consultation, but the physician reported a cessation of the progress of the disease six months later.

Case VII. Male, age 67. Only one eye affected, vision .6. At tho end of six months after one course of injections no progress could be noted.

Case VIIl. The history of this patient has been so remarkable that $I$ will close this paper by giving it more fully. A. B., a boy of five, was brought to me in the summer of 1874 . Three year's previously he was reported to have had a serious inflammation of the brain, during the progress of which his life was at one time despaired of. Since that time he had been somewhat deaf and rather backward. Vision of right oye had lately beeu found to be imperfect. 'Thero was complete white atrophy of the right optic nerve, no perception of light. The left nerve was of a grayish color, but vessels were full and vision appeared to be good. I did not see him again until 1881. His deafness aud backwardness had long sinco disappeared, but lu reading he was silid to hold his book cluse, as though he were near-sighted. Vision was now .4, visual field slightly but uniformly contracted, nerve as white as the other, but vessels fairly well filled. In 1885 vision was nearly .6; field as before (Fig. 1). In April, 1888, his central vision had fallen to .4, but a weak concave glass brought it up to nearly .7; field the same. In October, $18(12$, central vision and fundus remaining unchanged, there was found great diminution in the field (Fig. 2). Injections of strychnia were at once commenced, but the field narrowed steadily and rapidly, and Nov. 10 was as in Fig. 3 . The patient all the while felt poorly, was easily fatigued and lost weight. Dr. Walton, in consultation, found nothing, and considered the case a most unusual one. Another course of injections was now carried out, and the progress seemed arrested. His strength improved and there was even a slight increase in the length of the lield. In February, 1805, the field was found to be narrowing, and in May it had reached the size shown (Fig. 4). Strychnia repeated. Dr. Waltun again found no evidence of brain disease, and wrote: "It seems as if the strychuia treatment must have kept the trouble back materially." In November Dr. Walton found the kneo jerk normal and the general health considerabiy improved. On March 24, 1806, fiejd evidently again contracting; another course of strychnia and arrest of tho process; central vision the same. On April 1: there was another relapse, and the field now reached its maximum of contraction, narrowing to little more than a horizontal slit (Fig. 5). Another course of strychnia. Dr. Walton found no change in general health. In January, 1897, the field had slightly widened in a vertical direction. Twice since then there lias been a slight cluange for the worse, and each time a course of strychnia was started, the last being in Iray of that year. From that time forward the case has been simply kept under observation. His health is now good, contral vision between .7 and .8 , and the field has grown notably larger, a cousiderable change for the better having occurred during the present year (Fig. 6).

'Tie paticnt is now thirty-three years of age. He is a man of education and intelligeuce, and $b$ is enforced leisure has enabled his observation and comparison of his own symptoms to be thorough. At my request he called on mo a short time since, and I plaiuly asked him to state his mature judgment as to the effect of the strychnia injections. His reply was that in three iustances he considered the disease to have been distinctly checked, while in the other two "remarkable improvement" (I uso his own wurds) had followed.

As regards the technique of these injections I would say that I have been accustomed to make them in either temple alternately. Since using aseptic precautions I have never observed any local irritation. Previous to this abscesses were not uncommon. I begin with .04 of a gr. and add .01 daily, until constitutional effects are observed, expecting generally to reach at least the tenth injection. By that time the temples are apt to be a little sensitive, so I wait ten days and then repeat the course. In some few cases a third course of injections has been found of advantage.

To sum up the whole matter, I freely admit that these cases are not brilliant as to result. But the malady is in itself so fatal, and has been regarded as so hopeless, that it seems to me the smallest chance of relief, whether temporary or permanent, ought not to be allowed to slip.

The following conclusions are justifiable:

(1) Stryclinia is a stimulant to the optic nerve. Even in normal eyes it slightly increases the acuteness of vision and widens the visual field. These elfects are temporary (Fuchs). 


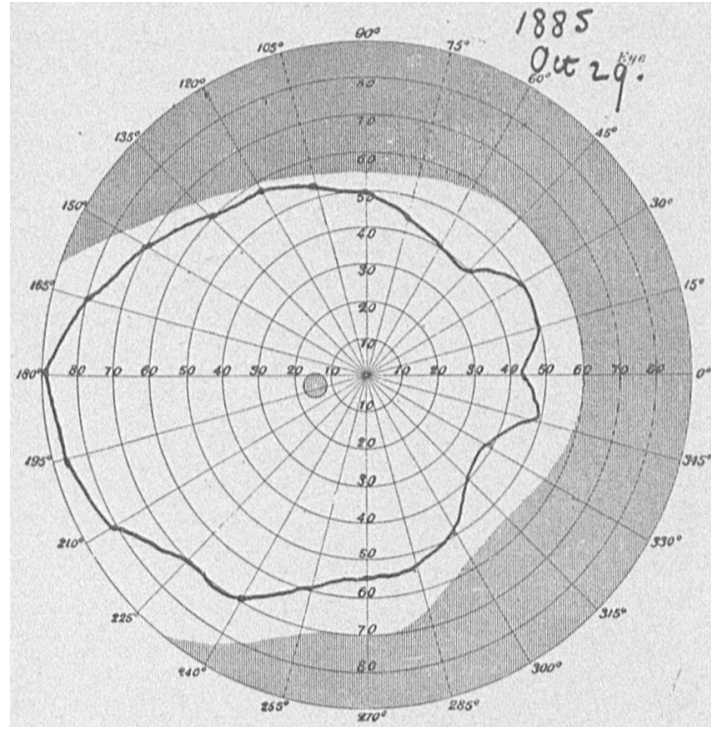

Fia. 1.

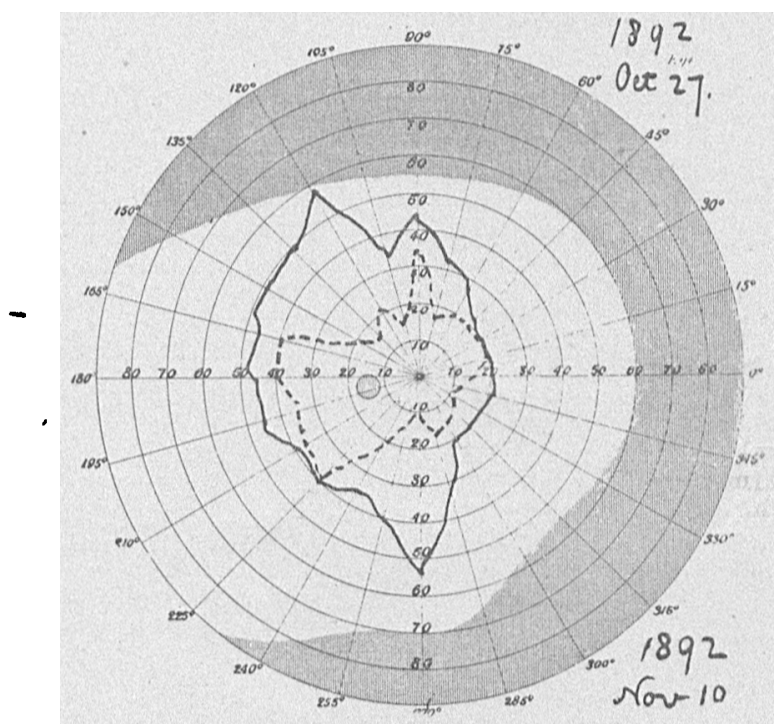

Fias. 2 and 3.
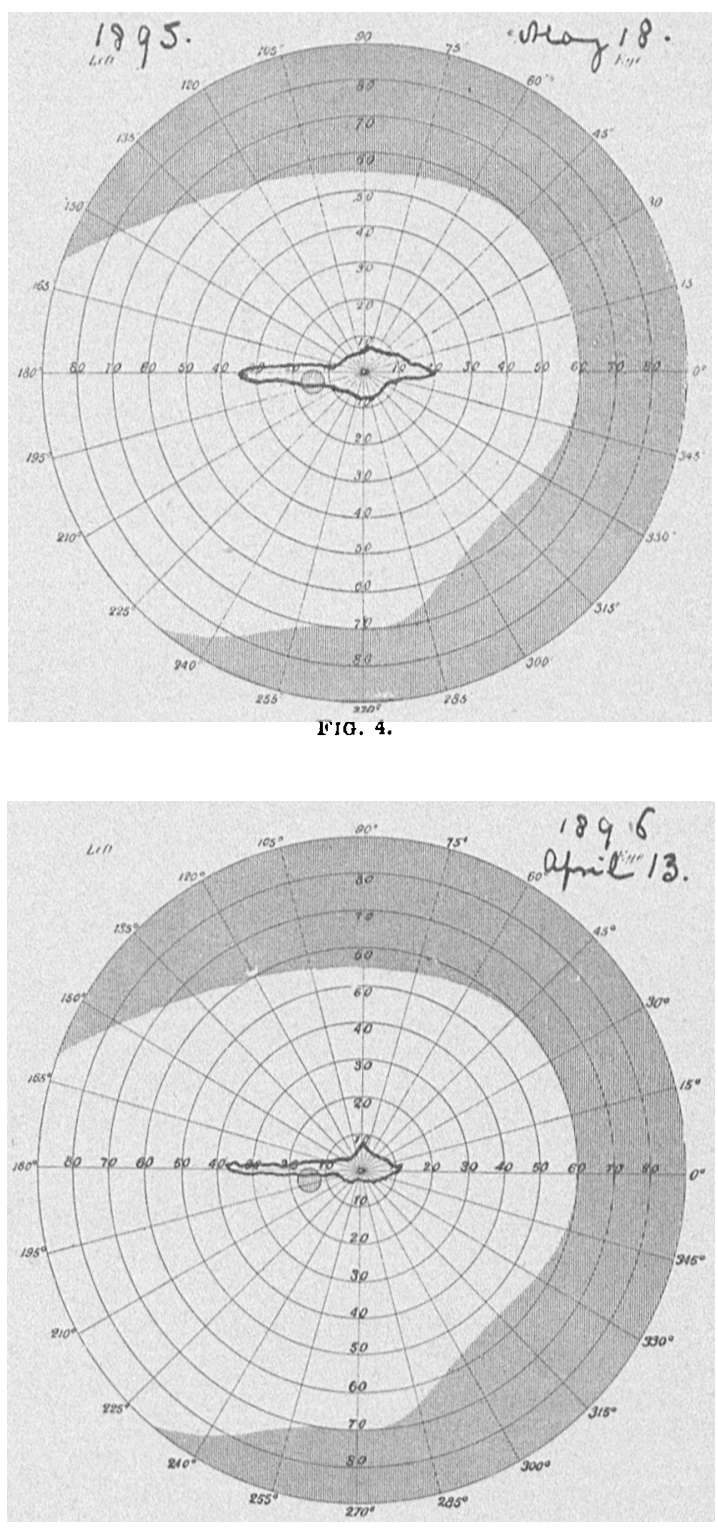

Fio. B.

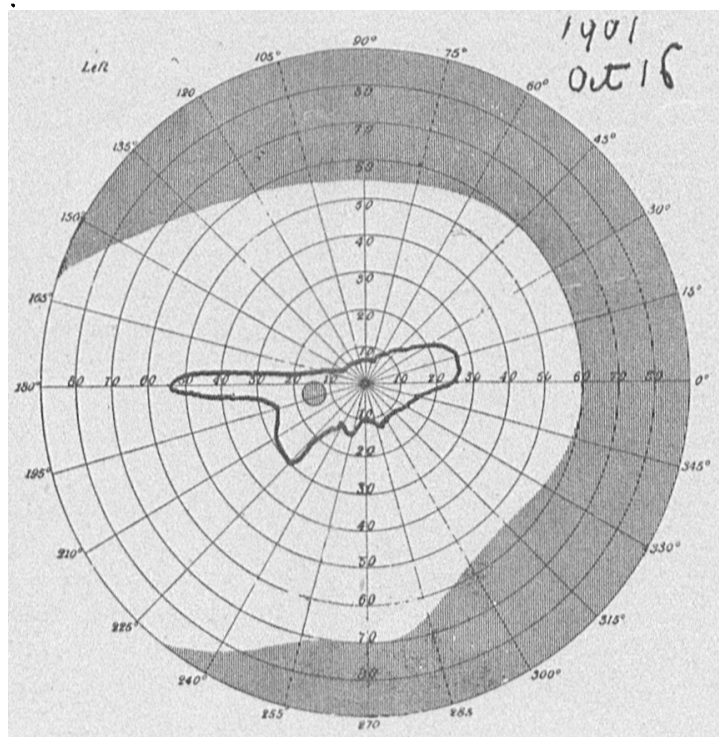

Fia. 6.

The Boston Medical and Surgical Journal as published by 
(2) In certain cases of optic nerve atrophy its local subcutaneous injection has, to say the least, coincided with an arrest in the progress of the disease, and has been followed by a somewhat increased acuteness of vision. Whether these effects are temporary or permanent, time and fuller statistics will show.

(3) In: a progressive case of this disease it is clearly our duty to state the above facts to the patient, and allow him to take the treatment if he is so inclined.

(4) The strychnia should always be administered in the temple, and by subcutancous injection.

CASE IX. On the day this paper was to bo presented I saw, through the kiudness of his plyysician, for the tirst time, a patient whose case seems to me remarkable. A young man, age 23, was attacked two years ago with progressivo optic nerve atrophy, and his vision vely rapidly declined. He saw several specialists here, and finally consulted Dr. Kalish of New York, who advised the strychuin treatment. This has since been carried on by Dr. Stickney of Arlington, from whom I have the following particulars: Commencing with $\frac{1}{30} \mathrm{gr}$. after each meal, by the mouth, and the same amount by injection in the temple daily ( ${ }^{4} \mathrm{gr}$. in al]) he went up in two months' time to of gr. after each meal and $8 \mathrm{gr}$. subcutaneously daily, making $1 \mathrm{gr}$. a day, and kept up this amount for one year. Now ho takes io gr. by injection, and $\frac{1}{8} \mathrm{gr}^{\mathrm{g}}$. to $30 \mathrm{gr}$. after each meal, making $1_{30}^{\prime \prime} \mathrm{gr}$. per day, and has kept this $\mathrm{ul}^{\prime}$ some months.

The patient, who is quite intelligent, tells me that his vision rapidly fell off in the outset, until treatinent - was commenced, and that then the progress of the disease appeared to be arrested. Dr. Stickney says that he was unable, a year or mure ago, to count fingers, but that he can now do this with either eyo; moreover, that he distinguishes some colors, sees the glass in his father's greenhouse and evon makes out tho leaves on the plants. The examination made by me showed typical and advanced optic norve atrophy in either eye. There is a small, lateral visual field in the right, with no central fixation. In the left there is central fixation and a very limited lateral field. Either eye counts fingers in the distance of about one metre. The left eye, of course, does this more easily than the right.

This patient has taken an unusual amount of strychnia and for an unusual length of time. In regard to its general effect Dr. Stickney writes as follows:

"I would add that only once did we have any marked evidences of the doses given being too Jarge, and then probably the subcutaneous dose of $\frac{1}{\mathrm{gr}} \mathrm{r}$. was given too near a dose of $\mathrm{gr}$. by the stomach. Judging by the rapid development of strychnia symptoms the subcutaneous dose of strychnia was probably injected into a vein. A spasm of the muscles in the back and legs camo on suddenly, patient foll bis full length on the sidewalk, rupturing the left membrana tympani. Bleeding from the ear, nose and throat came on, with vomiting for several hours. Intellect remained perfect throughout this time. In ten days pationt had recovered, and hearing was restored in three woeks. Of course tonics have been used more or less. At times tho pallor of face was marked and nitroglycerin was used with benefit."

Gifi' to the Lakeside Hospital, Cleveland. - Mr. J. H. Wade of Cleveland is reported to have recently announced a gift of $\$ 100,000$ to the Lakeside Hospital.
DISEASES OF THE EAR OF INTEREST TO INSURANCE EX.AMINEIS.*

BY PHLIP IAMMOND, M.D., BosTON,

Assistant in Otology, Harvard University; Assistant Aural Surgeon, Massachusetts Charitable kye and Kar Infrmary, etc.

There is considerable difference of opinion among the members of the profession as to what aural conditions constitute sufficient grounds for the rejection of an applicant as an undesirable risk. At the present time nearly all companies refuse to consider persons having a suppurative process in either ear, althongh some accept candidates who have had no discharge for three months. As I shall show later on, this rule is not a sufficient protection, inasmuch as there are certain conditions which favor recurrence of the disease.

It is interesting to note that although the intracranial complications of ear diseases are comparatively infrequent, they are exceedingly dangerous. Burkner ${ }^{1}$ found that ${ }^{3}$ of $1 \%$ of all ear patients die from otitic intracranial disease. These figures were also confirmed by Randall ${ }^{2}$ and Schwartze.

According to the records of Guy's Hospital, ${ }^{4}$ there were between the years 1869 to 188857 deaths from purulent ear disease out of 9,000 cases of all kinds, or about $\frac{2}{3}$ of $1 \%$. The records of a very much larger number of cases occurring in the Vienna General Hospital ${ }^{6}$ show that out of over 40,000 post-mortem examinations, 232 , or about $.58 \%$, died of aural complications.

No exact statistics are available as to the number of persons who die annually from ear diseases, but the list is undoubtedly a long one. Von Troltsch was of the opinion that a suppurative disease of the middle car was as serious a risk to accept as many cases of valvular heart disease, phthisis or hernia. Barr ${ }^{\circ}$ hardly concedes this, but believes all companies should inquire carefully as to the existence of any present or past suppuration, and that the actual condition of the ear should be taken into account in considering the expectation of life. The existence of a chronic discharge which persistently baffles all treatment should be considered as very unfavorable; a discharge which stops absolutely under treatment, leaving an open perforation, may be accepted conditionally; and a suppurative ear which heals by forming a new cicatricial drum may be accepted without reservation. In the latter case the ear is no more liable to future disease than it was originally, but in the case of an open perforation, the least drop of water entering through the drum, as, for instance, in bathing or a severe head cold, is apt to cause a renewal of the suppurative process.

The mere fact that the patient states that he has had a discharge from the ear should not necessarily militate against him, for all aurists of experience will recall cases where patients have applied for the relief of a discharge which examination has shown to be simply cerumen or, in other cases, due to the moist secretion of an ec-

* Read by Invitation at the Fourth Annual Dinner of the Medical Examiners of the Massachusetts Catholic Order of Foresters, Fob. 11, 1802. 